\title{
Book Review: The Power of Play in Higher Education: Creativity in Tertiary Learning
}

\author{
Aspasia Eleni Paltoglou* \\ Department of Psychology, Manchester Metropolitan University, Manchester, United Kingdom
}

Keywords: higher education, creativity, play, engagement, writing, experiment

A Book Review on

The Power of Play in Higher Education: Creativity in Tertiary Learning

Being a scholar involves being curious, studious and creative. But we also tend to see it as a serious endeavour. University students are adults that pay large amounts of money to go to university. University is serious business at a very crucial time of their lives where the students are transforming into specialists in what they have chosen to study in the hope of finding suitable employment after studying. Play, on the other hand, is often seen as childish and frivolous. Could it be relevant to university education?

Education introduces students to new ways of thinking and engaging with the world. Furthermore, learning at university is a creative endeavour; for example, students are asked to come up with novel studies and synthesize information from previous studies to back up arguments in their writing. Play allows the students to cultivate an open mindset that is conducive to active learning and creativity. This is one of the messages "The power of play in higher education: Creativity in tertiary learning" so powerfully conveys.

The book contains university educators' reflections on their attempts to introduce creative play in their units to engage and enthuse their students with their studies, as well as a discussion of theoretical models at the end. It could be viewed as a treasure trove of ideas for playful activities suitable for today's diverse student population, at a time when universities and the world of work are changing at an alarming pace.

The book consists of 42 chapters, organized in six broad sections: Trainers and Developers, Wanderers and Wonderers, Experimenters and Engagers, Wordsmiths and Communicators, Builders and Simulators, Gamers and Puzzlers, each section reflecting the focus of different playful interventions and the university courses and disciplines they are employed in.

I was particularly inspired by Chapter 2, where the authors provide a glimpse of a lively and spontaneous module they set up, one in which students are active contributors and co-creators. Among other things, students are encouraged to write a weekly blog, in order to establish a writing habit. In this chapter, but also throughout the book, the authors reflect on their attempts to enthuse their students with their studies, help them find their path, promote and celebrate the students' strengths and interests in a nurturing and empowering environment, instead of focusing on fixing deficits.

As one of the author notes, play makes the university experience less transactional, which links to the notion of "students as consumers" and its negative associations with academic performance (Bunce et al., 2017). Furthermore, "it allows students and staff to experiment, getting it wrong again and again before getting it right" (p31). Having a safe space to experiment, a space that helps one recover from failure, is important for development (Harford, 2012). Incorporating play in university creates such a space. One of the ways this is done is by focusing on the process rather than the product, something that is highlighted in Chapter 33.

Adding creative play to our teaching toolbox could also enhance employability. In Chapter 15, the author discusses the use of a simulation game to teach project management. The author notes 
that play enables the simulation of a work environment in a simplified, but vivid way. It evokes high levels of motivation from the students and allows them to develop important teamwork and communication skills as well as general competences. This example made me think that education is always a simulation of real life in some level, and play can increase the effectiveness of the simulation and as a result prepare students more effectively for the world of work.

Finally, the student journey is one of a transition from passive learning to more active learning. Play can help with this transition, which is something that is highlighted in the Playground model by Chrissi Nerantzi in the final chapter. Play can bring together cognitive, emotional and psychomotor elements of learning, making learning more relatable and a more holistic experience.

At times some more information about the case studies would have been useful. Furthermore, the contributors of the book mainly describe the sessions and some of the responses of the students, without providing formal qualitative or quantitative data investigating systematically the effects of the activities. However, it provides a good source of ideas for systematic studies on the use of play in higher education. A follow-up book could describe controlled experiments and other methods that test the effectiveness and efficacy of playful interventions in higher education and employability.

\section{REFERENCES}

Bunce, L., Baird, A., and Jones, S. E. (2017). The Student-As-Consumer Approach in Higher Education and its Effects on Academic Performance. Stud. Higher Educ. 42 (11), 1958-1978. available at: https://www.tandfonline.com/doi/full/ 10.1080/03075079.2015.1127908. doi:10.1080/03075079.2015.1127908

Harford, T. (2012). Adapt. Why success Always Starts with Failure. UK: Abacus.

Conflict of Interest: The author declares that the research was conducted in the absence of any commercial or financial relationships that could be construed as a potential conflict of interest.
This book provides some evidence that university educators are given the freedom to use play in their practice and make their teaching more creative and inclusive. Interestingly, Nerantzi points out that play is not the only way to enhance creativity in education, and that play should be viewed as one of the tools in our educational toolbox, rather than a panacea. That is an excellent point which illustrates the importance of equipping educators with a variety of educational methods that could help them provide high quality education for the students, and then giving these educators freedom to choose which ones to use at any given point. Funding bodies could prioritize funding for such interventions.

In summary, one of the main contributions of the book is that it provides a plethora of examples and frameworks for the use of play in university education. The enthusiasm of the authors is infectious. It is a book that reminds us how important it is to step back, reflect on our practice, explore new ways of teaching, and recognize what a privilege it is to be guiding individuals achieve their potential at university.

\section{AUTHOR CONTRIBUTIONS}

The author confirms being the sole contributor of this work and has approved it for publication.

Publisher's Note: All claims expressed in this article are solely those of the authors and do not necessarily represent those of their affiliated organizations, or those of the publisher, the editors and the reviewers. Any product that may be evaluated in this article, or claim that may be made by its manufacturer, is not guaranteed or endorsed by the publisher.

Copyright (C) 2021 Paltoglou. This is an open-access article distributed under the terms of the Creative Commons Attribution License (CC BY). The use, distribution or reproduction in other forums is permitted, provided the original author(s) and the copyright owner(s) are credited and that the original publication in this journal is cited, in accordance with accepted academic practice. No use, distribution or reproduction is permitted which does not comply with these terms. 